\title{
How effective are web 2.0 language learning sites in facilitating language learning?
}

\section{Billy Brick \\ Coventry University}

\section{Abstract}

This article discusses the new phenomena of Social Networking Sites (SNSs) for language learning and their implications for higher education. The strengths and weaknesses of these sites are identified and the potential to integrate some of the features of SNSs for language learning into the HE curriculum and the implications of this for educators are also discussed.

\section{Introduction}

There is a long tradition in language teaching of encouraging learners to communicate with others in their target language. Until recently this was often only possible with the class teacher, if indeed, they were native speakers themselves. One solution to this problem, advocated by teachers, was through penpalling and later keypalling.

This has recently changed with the advent of SNSs for language learning such as the websites Livemocha and Busuu which offer learners the opportunity to practise their target language (L2) in all of the four language learning skills: reading, writing, listening and speaking with other members of the community who are often native speakers of the L2.

The integration of SNSs into the HE curriculum faces some obstacles including:

- Lack of control over the curricula

- That many classes are taught in multiple occurrences which makes it diffi cult to implement change consistently

- That the majority of language classes are introductory and therefore the majority of learners will only have a basic knowledge of their chosen language. 
Godwin Jones (2005) has described SNSs as disruptive technologies in that they allow for new ways of carrying out familiar tasks. In the case of SNSs for language learning, this includes being able to practise speaking with native speakers and receiving almost instantaneous peer feedback on written and spoken submissions.

\section{Three potential models}

There are three different options for educators. The first option involves directing learners towards sites such as Livemocha and Busuu and suggesting they use the site to practise their language skills, leaving them free to proceed without further involvement from the tutor. The second option is based on a model suggested by Mullen, Appel and Shanklin (2009) who replicated some of the features of SNSs within a Moodle web where a class of Japanese learners met with a class of US learners and completed language learning exercises based on the principles of tandem learning. Both options provide opportunities for learners to practise their language skills: one of them in a public forum with no involvement from the tutor and the other in a more controlled environment where the tutor can monitor the amount of time learners spend communicating with their learning partners and can also suggest suitable exercises to complete. The third option is the institutional platform which allows the tutor to set up classes within the SNS. Livemocha have recently released their version and Busuu released theirs in September 2010.

\section{How do SNSs work?}

Language learning SNSs are characterised as having the following features: learner profiles containing details of language(s) spoken and target language(s), a profi le matching facility, free and premium learning materials, peer-review facilities for spoken and written feedback, and a points system to reward learning and peer-review.

Livemocha was the first of its kind and remains the most popular, with over five million members worldwide, mostly in the 18-35 age group (Livemocha, 2010) compared to its nearest competitor Busuu which has around 600,000 members. Livemocha members can take courses free of charge in 35 different languages with the option to pay for premium content in some of these.

The site is divided into four parts: home, learn, share and teach. In the home section (see Figure 1), learners can keep track of their progress, view their reward points, monitor their recent activity, view the work they have submitted for peer review and access requests from other community members to review their work. 


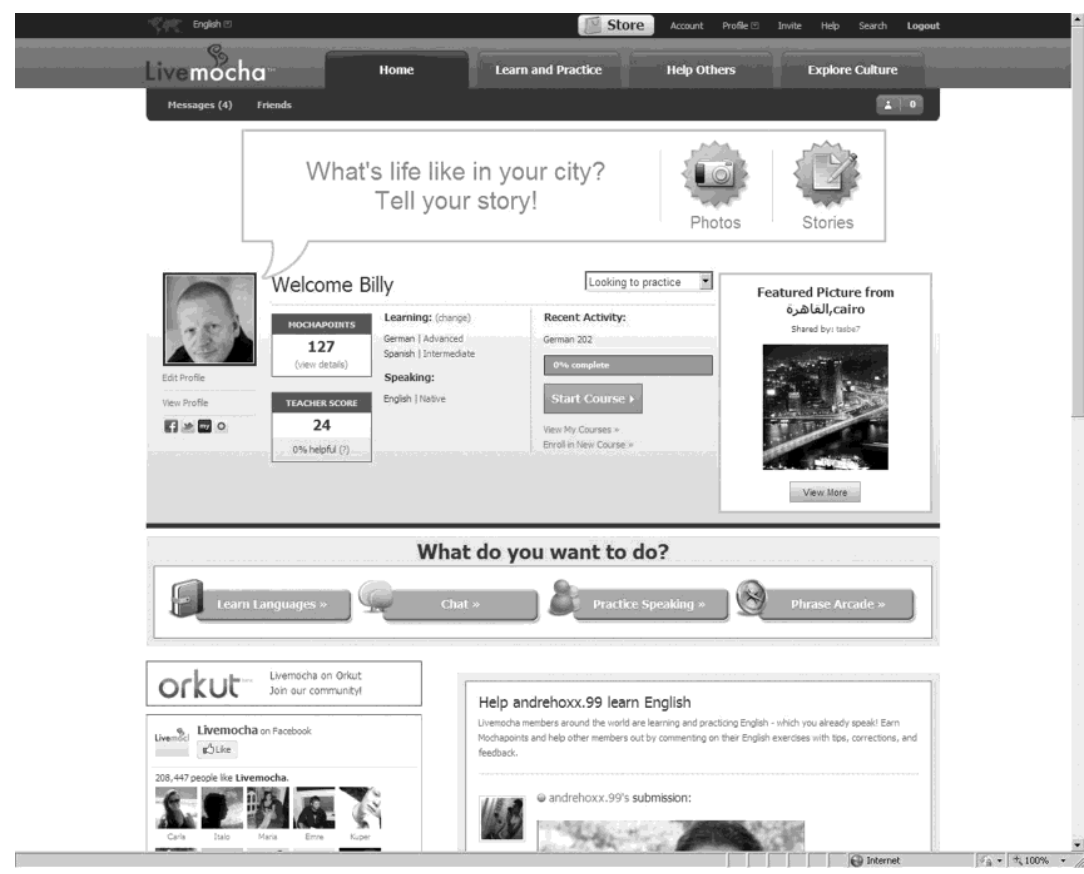

Figure 1 Home screen (@ 2010, Livemocha. Used with permission.)

In the learn section (Figure 2), learners are able to view the courses they are currently taking, create flashcards based on what they have learnt and further sections to view work submitted for review and for further practice. There are seven activities:

- Learn: learners listen and select the correct picture for vocabulary learning.

- Reading: learners read the sentence and select the correct picture.

- Listening: learners listen and select the correct picture.

- Magnet: learners listen and arrange words in a correct sentence.

- Writing: learners read the prompt, write an essay, and submit it to receive feedback from other anonymous users or their invited friends.

- Speaking: learners record a paragraph length discourse sample and submit it for peer review.

- Dialogue: learners practice a paragraph-length given dialogue with a partner of their choice.

The quality of the learning materials on the site has come in for some criticism. Jee and Park (2009) argue that, "The instructional content in the system could benefit from guidance from SLA [Second Language Acquisition] practitioners to improve its pedagogical design and offer a more systematic approach to effective learning". However, they acknowledged that Livemocha learners would benefit from the authentic communicative experience with native speakers, even without the presence of a tutor. 


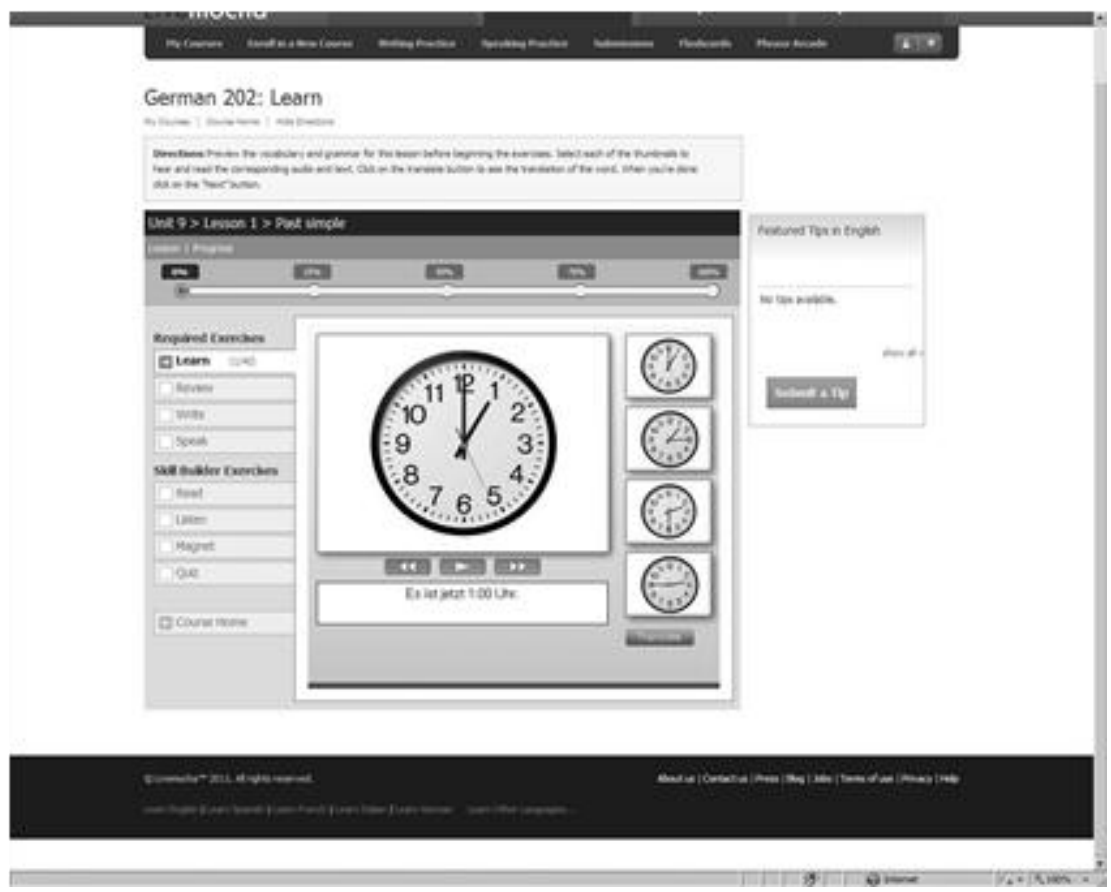

Figure 2 Learn screen (@ 2010, Livemocha. Used with permission.)

The share section (Figure 3), allows learners the opportunity to review submissions by other users and to provide feedback. It is in this section that learners are able to contribute to the community and in doing so earn 'mochapoints' and, eventually, 'medals'.

The teach tab encourages users to complete their profile in anticipation of increased functionality being added to the site in the near future. Few details have so far been provided but it is suggested that members with high Livemocha points ratings are likely to be offered the opportunity to teach on the site in exchange for money or Livemocha points.

Learners are encouraged to search for other learners on the site to engage in tandem learning with. This is supposed to offer mutual benefits to both parties as they can provide feedback for each other's oral or written work and communicate asynchronously, via an in-built texting tool, or synchronously, via a VolP tool. Built-in video-conferencing software allows users to communicate with friends within the site.

Peer review is at the centre of the design of the site, and 'mochapoints' are awarded to members who choose to review the written or oral submissions of other site members. This is one of the major attributes of SNSs for language learning and was one of the major points of discussion at the conference. On one hand, it can be diffi cult for learners to know whether their peers have provided constructive feedback. On 
the other hand, the feedback can be almost instantaneous and from multiple sources which allows users slowly develop a reliable network of 'friends'.

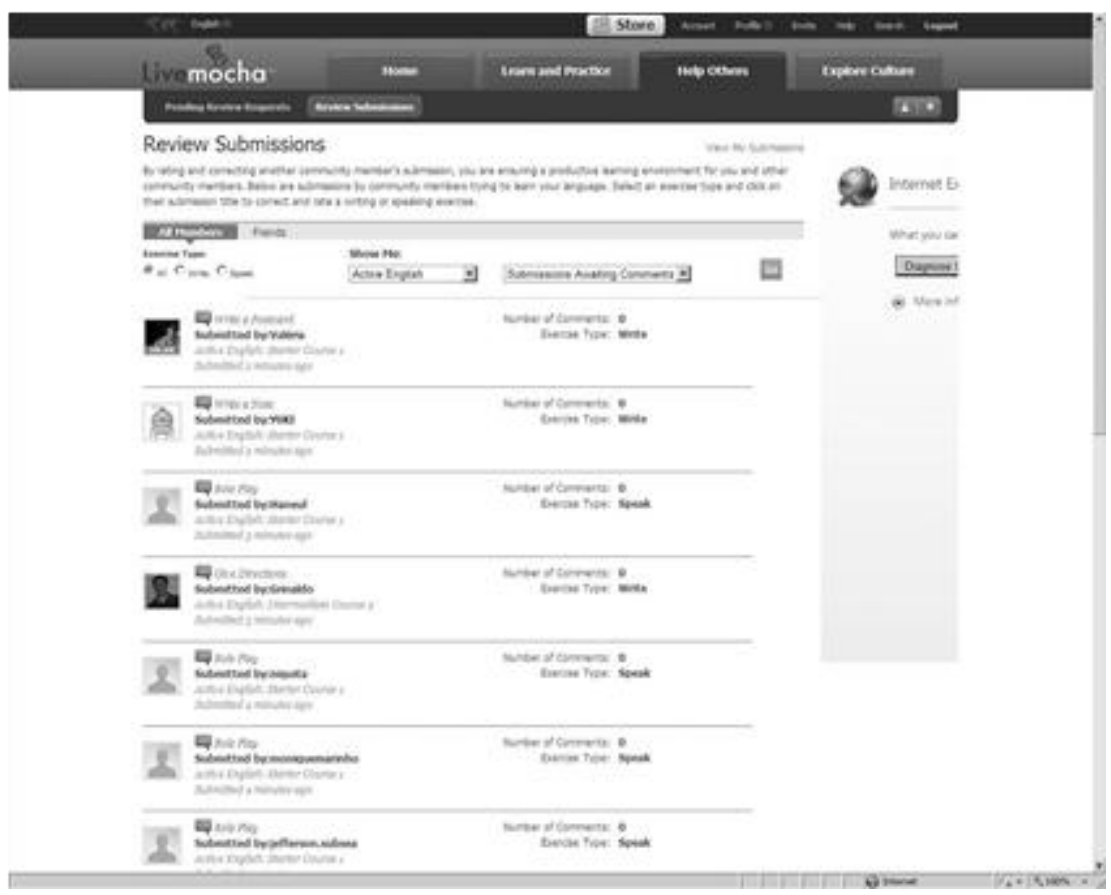

Figure 3 Share screen (@ 2010, Livemocha. Used with permission.)

The market for language learning is growing as a result of globalization, immigration and travel, and one of the founders of Livemocha, Krishnan Seshadrinathan (Livemocha, 2010), has predicted that over the next five years its service will become available on a variety of electronic devices, will offer 100 different languages, and will have between 30 and 50 million users. Whether these predictions are accurate remains to be seen, but it appears as though SNSs for language learning will play an important role in foreign language learning in the future.

This raises a number of questions for HE practitioners. Should these sites be integrated into the curriculum? If the answer to this question is yes, then how should we determine which site is the most suitable and what sort of guidance, if indeed any, should we provide for learners? If the answer is no, then should we consider recreating some of the features of these sites in a more controlled environment such as that described by Mullen, Appel and Shanklin (2009)? If we choose to reject SNSs in favour of more traditional methods, then do we run the risk of being unable to offer appropriate advice to learners practising their language skills in forums we are unfamiliar with? 


\section{Strengths and weaknesses}

Although Livemocha and Busuu are similar, the author has chosen to focus on a critique of Livemocha.com. The most common criticism levelled against SNSs for language learning concerns the quality and relevance of the free learning materials, which are based around a series of pictures and a complete lack of grammar teaching. Although the learning materials are poor, it is easy to understand why Livemocha have taken this approach. Materials based on word lists are particularly cheap to produce because it can be applied to all languages using the same prompts.

The lack of grammar exercises is also one of the main criticisms of the blogger Street-Smart Language Learning (2010), who reported on his attempt to study the German case system using Livemocha, and his eventual decision to abandon Livemocha in favour of other language learning web sites and books. He also goes on to mention that he had learnt German in the past and hoped to review the grammar rules he had previously learnt. Undoubtedly a beginner would fi nd learning grammar from Livemocha even more difficult.

The comments of the two bloggers Street-Smart Language Learning (2010) and Fluent in 3 months (2010) are both extremely critical of the free learning materials (neither comment on the premium content) but they agree that the site offers a unique opportunity for learners to practise their spoken skills with native speakers and that they facilitate almost immediate feedback.

A recent blog (Winkler, 2010) reveals that Busuu has released an iPhone app and predicts that Livemocha is likely to follow suit shortly. The review is on the whole positive and suggests that there is potential for SNSs for language learning to become embedded as part of language students' personal learning environments (PLEs) once these technologies become widely accessible.

Guo (2010) has stressed the importance of building motivation concepts such as immediacy and authenticity into language learning materials. SNSs offer both of these and according to Guo (2010) "The educational language website or computer application based on motivation is a true step forward as compared with inventions of printing, computer, the Internet and their applications to human language learning."

It may take time to develop a network of trusted partners within SNS sites and that this can only be built up on a trial and error basis. This addresses a common criticism often levelled against SNS for language learning: namely that the quality of the feedback is poor. The blogger Street-Smart Language Learning (2010) supports the idea that you have to develop a network of friends in whom you have confidence, "I now have a core group of tutors to whom I consistently submit such assignments to, and their feedback is phenomenal. They drill into my work to fi nd even subtle mistakes and offer excellent explanations of what 
I'm doing wrong. So, while initially you may fi nd that the feedback you get is not all that great, as you separate the wheat from the chaff you'll eventually end up with excellent tutors".

The blogger goes on to describe Livemocha as 'ingenious social engineering' because members are presented with work to correct immediately after they have had a piece of work corrected themselves. They then feel obliged to reciprocate by providing high quality feedback for someone who has done the same for them.

The National Student Surveys (NSS) has consistently received negative response regarding feedback. According to HEFCE (2009) only $57 \%$ of students considered it to be prompt and useful. Perhaps the quality of the feedback on SNSs for language learning is variable, depending on your network of friends, but it is almost immediate, often taking only a few minutes to arrive. This compares favourably with HE institutions where learners often have to wait several weeks for feedback.

\section{Conclusion}

The advent of SNSs for language learning has provided the opportunity, previously unavailable, for learners to practise oral skills with native speakers and to receive immediate feedback, thus justifying their designation as 'disruptive technologies' (Godwin-Jones, 2005). These two features are highly rated, as opposed to the learning materials which receive universal criticism. The number of sites and the number of people joining these sites continues to increase, even more premium content is likely to be offered and learners are now able to access the sites on various mobile platforms. In the face of ongoing cuts in HE, educators cannot afford to ignore SNSs for language learning. This has not gone unnoticed by Busuu who have launched a platform aimed specifically at universities. Practitioners will also need to be made aware of the various SNSs, so that they can evaluate them and select the one most suitable for their needs. Further research in this rapidly developing area is essential to enable practitioners to make informed choices with regard to their role in the curriculum.

\section{References}

Fluent in 3 months (2010). Busuu \& LiveMocha: review of pros and cons. Available online at:

www.fluentin3months.com/busuu-livemocha-review/ (Accessed 28 July, 2010)

Godwin-Jones, B. (2005) 'Emerging technologies: Skype and Podcasting. Disruptive technologies for language learning'. Language Learning \& Technology, 9(3), 9-12.

Guo, S. (2010) From printing to Internet, are we advancing in technological application to language learning? British Journal of Educational Technology Vol 41 No 2 E10-E16. 
Compass: The Journal of Learning and Teaching at the University of Greenwich, Issue 3, 2011

HEFCE (2009). The National Student Survey. Available online at:

www.hefce.ac.uk/learning/nss/data/2009/ (Accessed 28 July, 2010)

Jee, M.J. \& Park, M.J (2009) Livemocha as an online language-learning community, Calico Software Reviews. Available online at: https://calico.org/p-416-livemocha\%20as\%20an\%20online\%20languagelearning\%20community\%20\%28012009\%29.html (Accessed 23 March, 2010)

Livemocha (2010). Livemocha and Pearson Announce Partnership for Online Language Learning. Available online at: www.livemocha.com/pages/pr/03102009 (Accessed 24 March, 2010)

Mullen, T., Appel, C. \& Shanklin, T. (2009) Skype-based tandem language learning and web 2.0. In M. Thomas (Ed.), Handbook of research on Web 2.0 and second language learning (pp. 101-118). Hershey, PA: Igi Global.

Street-Smart Language Learning (2010). Livemocha review: love the native speakers, the method not so much. Available online at: www.streetsmartlanguagelearning.com/2009/01/livemocha-reviewlovenative-

speakers.html (Accessed 2 July, 2010)

Winkler, K. (2010) Blackberries on the iPhone - Busuu launches its Mobile Applications Best Customer. Available online at: www.kirstenwinkler.com/blackberries-on-the-iphone-busuu-launches-itsmobileapplications/ (Accessed 24 September, 2010) 